Ю. Л. Хлевна, к.т.н., дочент кафедри технологій управління, e-mail: yuliya.khlevna@gmail.com

Київський національний університет імені Тараса Шевченка вул. Володимирська, 60, Київ, 01033

\title{
МЕТОД ОЦНКИ ТА УПРАВЛІННЯ ВПЛИВАМИ НА ФОРМУВАННЯ КОНКРЕТИЗОВАНОЇ МЕТОДОЛОГІЇ УПРАВЛІННЯ ПРОЕКТАМИ
}

Основне джерело ефективного управління проектами - сучасні методології проектного менеджменту. Але їх впровадження, особливо в вітчизняній практиці, стикається з безліччю проблем, щео в результаті призводить до зневіри працівників підприємств у методології управління проектами. Пропонується вирішити июю проблему через створення мета-методологї управління проектами (ММУП). Вона буде забезпечувати створення орієнтованої на підприємство конкретизованої методологї̈ управління проектами (КМУП). В роботі виокремлено класи інструментів КМУП. Введено поняття коефіцієнта важливості інструменту КМУП для проектного управління. Показано, що кожен інструмент КМУП може бути отриманий з деякою ймовірністю, значення якої залежить від впливів ММУП. Запропоновано иілььову функиію оиінки змін в ймовірностях отримання інструментів КМУП. Розроблено метод підбору впливів ММУП на формування КМУП, який базується на: визначенні коефіиієнту важливості інструментів КМУП; формуванні групи експертів; формуванні множини керованих виливів; експертному методі формування інструментів КМУП без застосування ММУП та з урахуванням ММУП; розрахунку значення иільової функиї впровадження інструментів КМУП. Це дозволить відібрати позитивні впливи ММУП на формування КМУП та реалізувати їх на практиці при створенні систем управління проектами на проектно-орієнтованих підприємствах.

Ключові слова: мета-методологія, конкретизована методологія, вплив, інструменти мета-методології, проекти, управління проектами.

Постановка проблеми. Метаметодологія управління проектами (ММУП) $є$ основним інструментом впливу на проектноорієнтоване підприємств 3 метою удосконалення всіх процесів управління. Результатом використання ММУП є створення конкретизованої методології управління проектами (КМУП), що інтегрує інструменти, процеси, знання існуючих методологій управління проектами (МУП) з знаннями, інструментами та процесами конкретного підприємства. Але сама ММУП та КМУП не удосконалюють процеси управління. Ці методології дозволяють підібрати та впровадити ті методологічні інструменти, які найбільш ефективно покращують всі процеси управління, в першу чергу, процеси управління проектами (УП). Таким чином, мета-методологія базується на формалізованих інструментах впливу на різноманітні процеси, пов'язані із впровадженням методології управління проектами на проектноорієнтованому підприємстві. По суті, вона не лише забезпечує проектних менеджерівпрактиків шаблонами, правилами, алгоритма- ми, схемами, орієнтованими на вироблення у всіх учасників процесу впровадження позитивного мотивованого відношення до методології управління проектами, але й дозволяє вибирати саме ті інструменти, які найбільше впливають на підвищення ефективності діяльності проектно-орієнтованого підприємства. Разом 3 тим, неабияку роль при формуванні інструментів КМУП відіграють впливи. Тому необхідно вирішити наукову проблему ефективного управління впливами на формування конкретизованої умовами підприємства методології управління проектами.

Аналіз останніх досліджень і публікацій. Питання ролі різноманітних методологічних інструментів в управлінні проектами розглядалось в роботах [1-4]. Ключові питання впровадження методологій висвітлено у роботах [5, 6], ММУП та КМУП присвячено роботи [7-9]. Роль впливів при впровадженні методологій представлено у роботі [10]. Разом 3 тим, питання формування інструментів КМУП під дією впливів залишається відкритим. 
Метою статті $є$ розробка методу підбору впливів ММУП, які приведуть до створення такої конкретизованої методології управління проектами, яка дозволить підвищити ефективність управління проектами підприємства.

Виклад основного матеріалу. ММУП, КМУП та процеси виконання проектів пов'язані так, як показано на рисунку 1 .

Виходячи із представленої схеми, ММУП формує КМУП, конкретизована методологія, в свою чергу, має вплив на процеси управління, а процеси управління мають вплив на результати проектів. По суті, для успішного виконання проектів потрібно підібрати таку конфігурацію ММУП, яка дасть потрібні для управління проектами інструменти КМУП.

Під інструментами КМУП розуміють знання та вміння менеджерів виконувати функції $з$ управління та реалізації проектів, методики управління, методи та засоби реалізації функцій управління. В умовах ММУП такі інструменти ще не сформовані та не визначено роль впливів на їх формування.

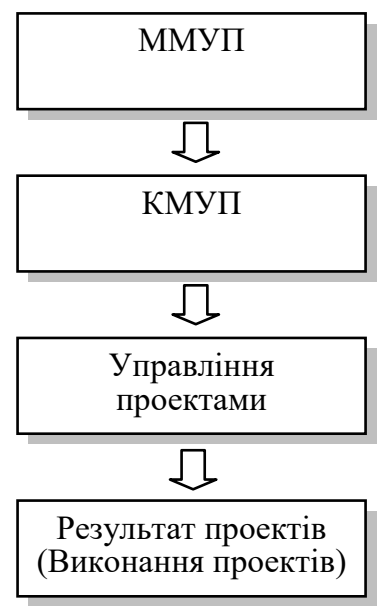

Рис. 1. Взасмодія ММУП, КМУП та процесів управління і виконання проектів

3 позиції КМУП виокремимо такі класи інструментів: організаційні $I_{o}$, технічні $I_{t}$, фiнансові $I_{f}$, та методологічні $I_{m}$.

Технічні інструменти КМУП, $I_{t}-$ інструменти, які базуються на основі використання знань технічних та програмних засобів підприємства, спрямовані на полегшення процесів ініціації, планування, виконання, аналізу, контролю та завершення проектів. Прикладом таких інструментів можуть бути: використання закритих каналів зв'язку, кор- поративних мереж та засобів зв'язку, сучасних стаціонарних та мобільних пристроїв, в які імплементовані програмні продукти управління проектами (Microsoft Project, Jira, GanttPro, Easy Redmine, тощо), системи управління інформацією та документацією (PrimaDoc, Аскод, та ін.) тощо.

Фінансові інструменти КМУП, $I_{f}$ - засоби, які передбачені фінансовою політикою підприємства. Сюди можна віднести: фінансові ресурси, стимули, санкції, страхові поліси, кредитні договори тощо.

Методологічні інструменти КМУП, $I_{m}-$ інструменти, які грунтуються на знаннях ММУП стосовно впровадження методологій управління проектами. Прикладами інструментів є: регламенти, інструкції, положення, розпорядження, накази.

Організаційні інструменти КМУП, $I_{o}$ охоплюють, як класичні, так і інноваційні інструменти управління проектами, пов'язані 3 роботою трудових ресурсів та управління ними, 3 процесами аутсорсингу, бенчмаркінгу, реінжинірингу. Крім того, вони уособлюють в собі функціонування інших інструментів, таких як технічні, фінансові та методологічні. Так, наприклад, створення офісу управління проектами (ОУП), можливе лише після підписання відповідного наказу та розробки положення про ОУП.

Наведені класи інструментів охоплюють підкласи та окремі елементи, які потрібно сформувати такими, щоб процеси управління та виконання проектів 3 найвищою ймовірністю давали потрібний результат. Вирішимо цю задачу.

Для того, щоб визначити, які впливи потрібно реалізувати, щоб найбільш потрібні інструменти сформувались, введемо коефіцієнт важливості інструменту КМУП для проектного управління $-\alpha_{j}$. Це забезпечить виокремлення саме тих інструментів, які потрібні при реалізації проекту впровадження МУП.

Звичайно, коли проектів впровадження МУП реалізується багато, в різних організаціях, то не завжди необхідне використання конкретного інструменту $I_{j}$. В цьому випадку буде змінюватись коефіцієнт $\alpha_{j}-$ від 0 (інструмент не потрібен), до 1 (без нього ніяк не можна). ММУП впливає на процес формування всіх інструментів. Причому, різні компоненти ММУП по різному. Одні впливають позитивно, інші негативно. Таким чином, можна говорити, що інструмент $I_{j}$, навіть якщо 
його важливість дорівнює 1, може бути отриманий $з$ деякою ймовірністю. Зрозуміло, що реалізація тих чи інших впливів робить цю ймовірність більшою, або меншою.

Опишемо узагальнений метод підбору раціональних впливів ММУП на формування КМУП. наступними кроками:

1. Визначення коефіцієнту важливості інструментів КМУП.

Будемо виходити 3 тих позицій, що коефіцієнт важливості інструментів КМУП отримано, і тепер важливо підібрати такі впливи ММУП, які зроблять ймовірність реалізації найбільш важливих інструментів максимальною. Задаймося таблицею важливості інструментів КМУП (табл. 1).

Функціонування наведених класів інструментів залежить від впливів ММУП. Такі впливи представлені у [10]. Якщо зобразити позитивні зміни проекту через вплив інструментів КМУП отримаємо цільову функцію:

$$
\sum_{j=1}^{4}\left[\alpha_{j} \cdot p_{j}+\left(1-\alpha_{j}\right) \cdot\left(1-p_{j}\right)\right] \rightarrow \max
$$

при обмеженнях

1) $0 \leq \alpha_{j} \leq 1$;

2) $p_{j}=f(M)$,

де $\alpha_{j}$ - коефіцієнт важливості інструменту КМУП $I_{j}$ для проектного управління;

$p_{j}$ - ймовірність отримання інструменту КМУП $I_{j}$;

$M$ - мета-методологія УП.

Таблиця 1

Важливість інструментів КМУП для проектного управління

\begin{tabular}{|l|c|}
\hline $\begin{array}{c}\text { Класи інструментів } \\
\text { КМУП }\end{array}$ & $\begin{array}{c}\text { Коерічієнт } \\
\text { важливості }\end{array}$ \\
\hline Технічні & $\alpha_{1}$ \\
\hline Фінансові & $\alpha_{2}$ \\
\hline Методологічні & $\alpha_{3}$ \\
\hline Організаційні & $\alpha_{4}$ \\
\hline
\end{tabular}

Дія впливів ММУП приведе до змін в ймовірностях формування інструментів КМУП. Ці зміни приведуть до досягнення чи до недосягнення цільового значення (1). Результати впливів ММУП можна представити у вигляді таблиць ймовірностей формування інструментів КМУП (табл. 2).
Таблиця 2

Ймовірність формування інструментів КМУП під впливом ММУП

\begin{tabular}{|l|c|c|c|c|c|}
\hline \multirow{2}{*}{$\begin{array}{c}\text { Класи } \\
\text { Кструментів } \\
\text { КМУП }\end{array}$} & $\alpha$ & $v_{1}$ & $v_{2}$ & $\ldots$ & $v_{n}$ \\
\hline Технічні & $\alpha_{1}$ & $p_{1,1}$ & $p_{2,1}$ & $\ldots$ & $p_{n, 1}$ \\
\hline Фінансові & $\alpha_{2}$ & $p_{1,2}$ & $p_{2,2}$ & $\ldots$ & $p_{n, 2}$ \\
\hline Методологічні & $\alpha_{3}$ & $p_{1,3}$ & $p_{2,3}$ & $\ldots$ & $p_{n, 3}$ \\
\hline Організаційні & $\alpha_{4}$ & $p_{1,4}$ & $p_{2,4}$ & $\ldots$ & $p_{n, 4}$ \\
\hline
\end{tabular}

Наведена таблиця, якщо вона буде наповнена конкретними значеннями може стати основою для вибору тих впливів ММУП, які забезпечать отримання потрібних інструментів КМУП з найвищою ймовірністю. По суті вона стане основою управління процесом впровадження МУП. Але для вирішення цієї задачі необхідно:

1. Наповнити наведену таблицю конкретними значеннями.

2. Розробити метод управління впровадженням МУП, який дозволить на основі представленої в табл. 1 і табл. 2 інформації розробити раціональну стратегію реалізації впливів ММУП на інструменти КМУП. Що, в свою чергу, дозволить максимізувати вираз (1).

Для наповнення табл. 1-2 конкретними значеннями можна використати як статистичні, так і експертні методи. Для застосування статистичних методів необхідно мати інформацію про інструменти КМУП та впливи ММУП. В реальних умовах цього досягти важко. Тому пропонується використати експертні методи для отримання значень суб'єктивних ймовірностей, що визначатимуть можливість отримання потрібних інструментів КМУП під дією впливів ММУП.

1. Формування групи експертів. Пропонується дві групи експертів: експерти науковці $\left(m_{H}\right)$ та практики $\left(m_{n}\right)$. Визначення величини довіри експертам науковцям $\left(a_{i}^{\text {наук }}\right)$ та експертам-практикам $\left(a_{i}^{\text {практ }}\right)$.

2. Формування множини керованих впливів $V_{d}[10]$.

3. Експертна оцінка ймовірності формування інструментів КМУП без застосування ММУП (без впливів ММУП).

Експерти вказують суб'єктивні ймовірності того, що наведені інструменти будуть використовуватись і без застосування ММУП. 
Результати експертного оцінювання представлені в таблиці 3.

Таблиця 3

Результати суб'сктивних ймовірності використання інструментів КМУП без застосування ММУП

\begin{tabular}{|l|c|c|c|c|c|}
\hline $\begin{array}{c}\text { Класи } \\
\text { інструмен- } \\
\text { тів КМУП }\end{array}$ & $\begin{array}{c}\text { Екс- } \\
\text { перт } 1\end{array}$ & $\ldots$ & $\begin{array}{c}\text { Екс- } \\
\text { перт } i\end{array}$ & $\ldots$ & $\begin{array}{c}\text { Експерт } \\
m_{H}+m_{n}\end{array}$ \\
\hline Технічні & $e_{0,1}(1)$ & $\ldots$ & $e_{0,1}(i)$ & $\ldots$ & $e_{0,1}\left(m_{n}+m_{n}\right)$ \\
\hline Фінансові & $e_{0,2}(1)$ & $\ldots$ & $e_{0,2}(i)$ & $\ldots$ & $e_{0,2}\left(m_{u}+m_{n}\right)$ \\
\hline $\begin{array}{l}\text { Методоло- } \\
\text { гічні }\end{array}$ & $e_{0,3}(1)$ & $\ldots$ & $e_{0,3}(i)$ & $\ldots$ & $e_{0,36}\left(m_{H}+m_{n}\right)$ \\
\hline $\begin{array}{l}\text { Організа- } \\
\text { ційні }\end{array}$ & $e_{0,4}(1)$ & $\ldots$ & $e_{0,4}(i)$ & $\ldots$ & $e_{0,4}\left(m_{\mu}+m_{n}\right)$ \\
\hline
\end{tabular}

3 цієї інформації можна розрахувати середньозважену початкову ймовірність отримання інструментів КМУП:

$$
p_{0, j}=\frac{\sum_{i=1}^{m_{n}}\left(\alpha_{i}^{\text {практ }} \cdot e_{0, j}(i)\right)+\sum_{i=1}^{m_{n}}\left(\alpha_{i}^{\text {паук }} \cdot e_{0, j}\left(m_{n}+i\right)\right)}{\sum_{i=1}^{m_{n}} \alpha_{i}^{\text {nракm }}+\sum_{i=1}^{m_{n}} \alpha_{i}^{\text {паулk }}},
$$

де $p_{0}$

- середньозважена початкова ймовірність отримання інструменту КМУП $I j$.

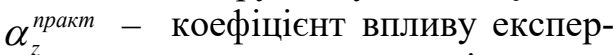
та-практика $z$ на рішення;

$\alpha_{r}^{\text {наук }}-$ коефіцієнт впливу експерта-науковця $r$ на рішення.

Виходячи 3 того, що впливи ММУП змінюють ймовірності формування інструментів КМУП пропонується наступний метод управління впливами на формування інструментів КМУП.

1. Розрахунок нової ймовірності формування інструментів КМУП (під дією впливiв).

Для отримання таблиці впливів на підбір інструментів КМУП експерти-практики вказують збільшиться ймовірність (покращиться ситуація 3 впровадженням МУП) чи зменшиться (погіршиться) під дією впливів. Для цього експерти-практики вказують, чи буде впроваджено деякий інструмент КМУП, залежно від дії впливу.

Експерти проставляють значення:

$$
\forall v_{k} \in V, y_{j, i}\left(v_{k}\right)=\{-1,0,1\},
$$

де

$$
y_{j, i}\left(v_{k}\right)=-1-\quad \begin{aligned}
& \text { iнструмент не буде } \\
& \text { впроваджено; }
\end{aligned}
$$

$$
\begin{aligned}
& y_{j, i}\left(v_{k}\right)=0 \quad-\quad \text { не впливає на впрова- } \\
& \text { дження інструменту; } \\
& y_{j, i}\left(v_{k}\right)=1-\quad \begin{array}{l}
\text { інструмент } \\
\text { впроваджено }
\end{array}
\end{aligned}
$$

Результати впровадження інструментів КМУП, залежно від дії впливів представлені в таблиці 4.

Виходячи 3 введених експертних оцінок результатів проекту впровадження МУП (див. табл. 4) та враховуючи рівень впливовості цих експертів, отримаємо спільну експертну оцінку можливості формування інструментів КМУП:

$$
\begin{gathered}
\overline{p_{0, J}}=0.5+\frac{\sum_{i=1}^{m_{n}}\left[a_{i}^{\text {практ }} \cdot \sum_{k=1}^{q} y_{j, i}\left(v_{k}\right)\right]}{2 \cdot q \cdot \sum_{i=1}^{m_{n}}\left[a_{i}^{\text {практ }}\right]} . \\
\cdot \frac{\sum_{i=1}^{m_{n}}\left[a_{i}^{\text {практ }}\right]}{m_{n}}=0.5+\frac{\sum_{i=1}^{m_{n}}\left[a_{i}^{\text {практ }} \cdot \sum_{k=1}^{q} y_{j, i}\left(v_{k}\right)\right]}{2 \cdot q \cdot m_{n}},
\end{gathered}
$$

де $\overline{p_{0, j}}-$ відносна суб'єктивна ймовірність впровадження інструменту $I j$.

В формулі (3) коефіцієнт

$$
\frac{\sum_{i=1}^{m_{n}}\left[a_{i}^{\text {практ }}\right]}{m_{n}}
$$

визначає міру довіри до всіх експертів (ймовірність того, що вони праві).

Результати відносної суб'єктивної (нової) ймовірності впровадження інструменту $I j$ представлені в таблиці 5.

Нові ймовірності формування інструментів КМУП дають уявлення про те, наскільки впливатиме ММУП на управління проектом впровадження МУП.

Таблиця 4

Результати експертного оцінювання впливу $v_{\boldsymbol{k}}$ експертами-практиками (збільшиться чи зменшиться ймовірність формування інструментів КМУП під дією заданого впливу)

\begin{tabular}{|l|c|c|c|c|c|c|}
\hline \multicolumn{1}{c|}{$\begin{array}{c}\text { Класи } \\
\text { інструмен- } \\
\text { тів КМУП }\end{array}$} & $\alpha$ & \multicolumn{5}{|c|}{ Експерти-практики } \\
\cline { 3 - 8 } & $E_{1}$ & $\ldots$ & $E_{i}$ & $\ldots$ & $E_{m_{n}}$ \\
\hline Технічні & $\alpha_{1}$ & $y_{1,1}\left(v_{k}\right)$ & $\ldots$ & $y_{1, i}\left(v_{k}\right)$ & $\ldots$ & $y_{1, m_{n}}\left(v_{k}\right)$ \\
\hline Фінансові & $\alpha_{2}$ & $y_{2,1}\left(v_{k}\right)$ & $\ldots$ & $y_{2, i}\left(v_{k}\right)$ & $\ldots$ & $y_{2, m_{n}}\left(v_{k}\right)$ \\
\hline $\begin{array}{l}\text { Методоло- } \\
\text { гічні }\end{array}$ & $\alpha_{3}$ & $y_{3,1}\left(v_{k}\right.$ & $\ldots$ & $y_{3, i}\left(v_{k}\right)$ & $\ldots$ & $y_{3, m_{n}}\left(v_{k}\right)$ \\
\hline $\begin{array}{l}\text { Організа- } \\
\text { ційні }\end{array}$ & $\alpha_{4}$ & $y_{4,1}\left(v_{k}\right.$ & $\ldots$ & $y_{4, i}\left(v_{k}\right)$ & $\ldots$ & $y_{4, m_{n}}\left(v_{k}\right)$ \\
\hline
\end{tabular}


Нова ймовірність впровадження

Таблиця 5 інструментів КМУП

\begin{tabular}{|l|c|}
\hline $\begin{array}{c}\text { Класи інструментів } \\
\text { КМУП }\end{array}$ & $\begin{array}{c}\text { Експертна ймовірність } \\
\text { формування інструме- } \\
\text { нту КМУП }\end{array}$ \\
\hline Технічні & $\overline{p_{0,1}}$ \\
\hline Фінансові & $\overline{p_{0,2}}$ \\
\hline Методологічні & $\overline{p_{0,3}}$ \\
\hline Організаційні & $\overline{p_{0,4}^{\prime}}$ \\
\hline
\end{tabular}

2. Розрахунок впливу виконаємо через співпадіння початкової ймовірності використання інструментів КМУП, та ймовірності їх використання після впровадження МУП

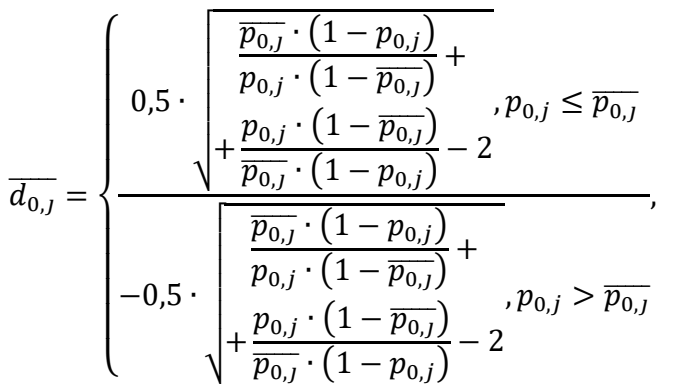

де $\overline{d_{0, j}}-$ величина впливу на впровадження інструменту Ij.

Результат зведемо в таблицю 6.

Вплив на формування інструментів КМУП, визначений експертами-практиками

\begin{tabular}{|l|c|}
\hline $\begin{array}{c}\text { Класи інструментів } \\
\text { КМУП }\end{array}$ & $\begin{array}{c}\text { Вплив на формування } \\
\text { інструментів КМУП }\end{array}$ \\
\hline Технічні & $\overline{d_{0,1}}$ \\
\hline Фінансові & $\overline{d_{0,2}}$ \\
\hline Методологічні & $\overline{d_{0,3}}$ \\
\hline Організаційні & $\overline{d_{0,4}}$ \\
\hline
\end{tabular}

Знаючи суб'єктивну ймовірність формування інструментів КМУП (див. табл. 5) та коефіцієнти важливості цих інструментів (див. табл. 1), можна знайти значення цільової функції (1).

Але таблиця 5 формується на основі інформації експертів-практиків. Тепер важливо ще їх порівняти 3 думкою експертівнауковців. Але на відміну від практиків, які знають, що буде мінятися в компанії при впровадженні тих чи інших інструментів, науковці швидше можуть оцінити кінцевий результат впровадження (а не його хід). Тому їм було запропоновано представити результат формування інструментів КМУП в проекті впровадження МУП. Суб'єктивні ймовірності формування інструментів КМУП під дією впливів ММУП представлено у таблиці 7.

Таблиця 7

\section{Результати експертного оцінювання} впливу $\boldsymbol{v}_{\boldsymbol{k}}$ експертами-науковцями

(нові суб'єктивні ймовірності формування інструментів КМУП під дією впливів ММУП)

\begin{tabular}{|l|c|c|c|c|c|c|c|}
\hline \multirow{2}{*}{$\begin{array}{c}\text { Класи } \\
\text { інструме- } \\
\text { нтів }\end{array}$} & $\alpha$ & $p_{0, j}$ & $E_{1}$ & $\ldots$ & $E_{i}$ & $\ldots$ & $E_{m_{n}}$ \\
\cline { 3 - 8 } & & & \multicolumn{5}{|c|}{ Експерти } \\
\hline Технічні & $\alpha_{1}$ & $p_{0,1}$ & $e_{1,1}\left(v_{k}\right)$ & $\ldots$ & $e_{1, i}\left(v_{k}\right)$ & $\ldots$ & $e_{1, m_{n}}\left(v_{k}\right)$ \\
\hline Фінансові & $\alpha_{2}$ & $p_{0,2}$ & $e_{2,1}\left(v_{k}\right)$ & $\ldots$ & $e_{2, i}\left(v_{k}\right)$ & $\ldots$ & $e_{2, m_{n}}\left(v_{k}\right)$ \\
\hline $\begin{array}{l}\text { Методо- } \\
\text { логічні }\end{array}$ & $\alpha_{3}$ & $p_{0,3}$ & $e_{3,1}\left(v_{k}\right)$ & $\ldots$ & $e_{3, i}\left(v_{k}\right)$ & $\ldots$ & $e_{3, m_{n}}\left(v_{k}\right)$ \\
\hline $\begin{array}{l}\text { Організа- } \\
\text { ційні }\end{array}$ & $\alpha_{4}$ & $p_{0,4}$ & $e_{4,1}\left(v_{k}\right)$ & $\ldots$ & $e_{4, i}\left(v_{k}\right)$ & $\ldots$ & $e_{4, m_{n}}\left(v_{k}\right)$ \\
\hline
\end{tabular}

Середньозважена ймовірність формування інструментів КМУП під дією впливу $v_{k}$, яка проставляється експертами-науковцями розраховується за формулами:

$$
\overline{p_{0, j}\left(v_{k}\right)}=\frac{\sum_{i=1}^{m_{n}}\left(\alpha_{i}^{\text {nayk }} \cdot e_{j, i}\left(v_{k}\right)\right)}{\sum_{i=1}^{m_{n}} \alpha_{i}^{\text {\#ayk }}},
$$

де

$$
\begin{aligned}
\overline{p_{0, j}\left(v_{k}\right)}- & \text { середньозважена ймо- } \\
& \text { вірність формування } \\
& \text { інструменту КМУП } I_{j} \\
& \text { після впливу } v_{k} .
\end{aligned}
$$

По різниці між наведеними в таблицях 3 і 7 ймовірностями (після впливів та до впливів ММУП) визначимо величину самого впливу на формування інструменту КМУП:

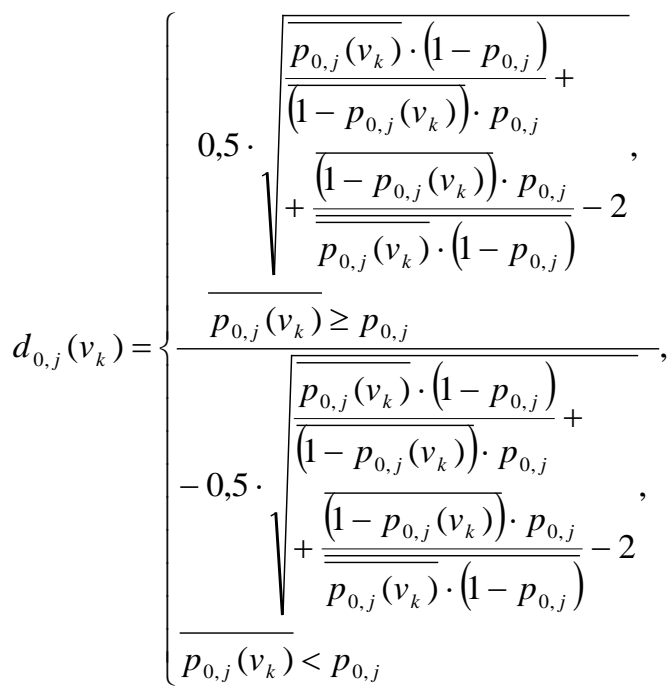


де

$$
\begin{aligned}
d_{0, j}\left(v_{k}\right)- & \text { величина впливу } v_{k} \text { на } \\
& \text { можливість формування } \\
& \text { інструменту КМУП } I_{j} .
\end{aligned}
$$

Тепер визначимо суму всіх впливів

$$
\overline{\overline{d_{0, j}}}=\sum_{k=1}^{q} d_{0, j}\left(v_{k}\right)
$$

де

$$
\begin{aligned}
\overline{\overline{d_{0, j}}}- & \text { оцінка експертами- } \\
& \text { практиками впливу на мож- } \\
& \text { ливість формування інстру- } \\
& \text { менту КМУП } I_{j} .
\end{aligned}
$$

Загальний вплив визначимо як середне значення отриманих в (6) та в (7).

$$
\begin{aligned}
D_{0, j} & =\frac{\overline{d_{0, j}}+\overline{d_{0, j}}}{2}, \\
\text { де } D_{0, j}- & \text { оцінка } \\
& \text { практиками i } \\
& \text { науковцями впливу на момеж- } \\
& \text { ливість формування інстру- } \\
& \text { менту КМУП } I_{j} .
\end{aligned}
$$

3. Знаючи початкову суб'єктивну ймовірність формування інструментів КМУП та величину впливу (реалізовану за експертними оцінками), можна визначити ймовірність формування інструменту КМУП:

$$
\begin{aligned}
& \overline{\overline{p_{0, j}}}=\frac{p_{0, j} \cdot\left(0,5+\frac{D_{0, j}}{2 \cdot \sqrt{\left(D_{0, j}\right)^{2}+1}}\right)}{p_{0, j} \cdot\left(0,5+\frac{D_{0, j}}{2 \cdot \sqrt{\left(D_{0, j}\right)^{2}+1}}\right)+\left(1-p_{0, j}\right) \cdot\left(0,5-\frac{D_{0, j}}{2 \cdot \sqrt{\left(D_{0, j}\right)^{2}+1}}\right)}= \\
& =\frac{p_{0, j} \cdot\left(D_{0, j}+\sqrt{\left(D_{0, j}\right)^{2}+1}\right)}{p_{0, j} \cdot\left(D_{0, j}+\sqrt{\left(D_{0, j}\right)^{2}+1}\right)+\left(1-p_{0, j}\right) \cdot\left(\sqrt{\left(D_{0, j}\right)^{2}+1}-D_{0, j}\right)},
\end{aligned}
$$

де $\overline{\overline{p_{0, j}}}$ - спільна оцінка експертаминауковцями та експертамипрактиками ймовірності формування інструменту КМУП $I_{j}$.

$D_{0, j} \quad$ - оцінка експертамипрактиками i експертаминауковцями впливу на можливість формування інструменту КМУП $I_{j}$.

$p_{0, j} \quad-$ середньозважена початкова ймовірність отримання інструменту КМУП Ij.

4. Розрахунок значення цільової функціï 1 по отриманим ймовірностям впровадження інструментів КМУП.

5. Якщо значення цільової функції більше 0 - відбір впливу.

6. Завершення розрахунку.
Висновки. Виокремлено технічні, фінансові, методологічні та організаційні інструменти КМУП. Введено поняття коефіцієнта важливості інструменту КМУП для проектного управління. Встановлено, що формування та функціонування наведених інструментів залежить від впливів ММУП. Показано, що кожен інструмент КМУП може бути отриманий 3 деякою ймовірністю, значення якої залежить від впливів ММУП. Запропоновано цільову функцію оцінки змін в ймовірностях отримання інструментів КМУП. Розроблений метод підбору впливів ММУП на формування КМУП, який базується на: визначенні коефіцієнту важливості інструментів КМУП; формуванні групи експертів; формуванні множини керованих впливів; експертному методі формування інструментів КМУП без застосування ММУП та 3 врахуванням ММУП; розрахунку значення цільової функції впровадження інструментів КМУП. Таким чином можна буде відібрати позитивні впливи ММУП на формування КМУП та реалізувати їх на практиці при створенні систем управління проектами на проектно-орієнтованих підприємствах.

\section{Список літератури}

1. Федорчак О. В. Інноваційні інструменти управління цільовими програмами та проектами. Державне будівництво. 2012. № 2 C. 2-13.

2. Бондар-Підгурська О. В. Реінжиніринг як універсальний інструмент інноваційного розвитку економіки. Проблеми економіки. 2014. № 4. C. 84-90.

3. Бачевська І. П. Інноваційна діяльність в Україні: інструменти та механізми державного впливу. URL: http://www.dbuapa. dp.ua/zbirnik/2014-02(12)/11.pdf.

4. Медведєва О. М. Фактологічний базис управління взаємодією в проектних ситуаціях. Управління розвитком складних систем. 2012. Вип. 10. С. 61-71.

5. Бушуев С. Д., Бушуева Н. С., Неизвестный С. И. Механизмы конвергенции методологий управления проектами. Управління розвитком складних систем. 2012. №11. C. 5-13.

6. PM GUIDE 01 Selecting a project management methodology / Enterprise Solutions. Victorian Government Cio Council, 2014. URL: http://www. enterprisesolu- 
tions.vic.gov.au/wp-content/ uploads/2014/07/ PM-GUIDE-01-Project-managementmethodology-selection-guideline.pdf.

7. Тесля Ю. М., Хлевна Ю. Л. Структура знань в мета-методології управління проектами. Управління розвитком складних систем. 2017. № 29. С. 78-85.

8. Хлевна Ю. Л. Створення та використання мета-методології управління проектами в умовах кризи. XVI Міжнародна науковопрактична конференція: Управління проектами розвитку суспільства, КНУБА C. $199-200$.

9. Тесля Ю. М., Х Хлевна Ю. Л., Оберемок Н. В. Управління створенням конкретизованої методології управління проектами. Управління проектами, системний аналіз і логістика. Ч.1: Серія "Технічні науки» К.: НТУ, 2016. Вип. 18. С. 115-125.

10.Тесля Ю. М., Хлевна Ю. Л., Сгорченкова Н. Ю., Кошелева Д. І. Впливи на формування конкретизованої методології управління проектами. Вісник Черкаського державного технологічного університету. Серія: Технічні науки. 2017. № 2. С. 45-54.

\section{References}

1. Fedorchak,. O. V. (2012) Innovative tools for managing target programs and projects State building. 2012. No. 2. Kyiv, pp. 134-137 [in Ukrainian].

2. Bondar-Podgurska, O. V. (2014) Reengineering as a universal tool for innovation development of the economy. Problems of Economics, pp. 84-90 [in Ukrainian].

3. Bachevskaya I. P. (2014) Innovative activity in Ukraine: tools and mechanisms of state influence URL: http://www.dbuapa.dp.ua/ zbirnik/2014-02(12)/11.pdf.
4. Medvedeva, O. M. (2012) Factual basis of interaction management in design situations. Management of complex systems development, exp. 10, pp. 61-71 [in Ukrainian].

5. Bushuev, S. D., Bushueva, N. S., Neizvesniy, S. I. (2012). Convergence mechanisms of project management methodologies. Management of development of complex system, 11, 5-13 [in Russian].

6. PM GUIDE (2014) 01 Selecting a project management methodology. Enterprise Solutions. - Victorian Government Cio Council, URL:http://www.enterprisesolutions.vic.gov.a u/wp-content/uploads/2014/07/ PM-GUIDE01-Project-management-methodologyselection-guideline.pdf.

7. Teslya, I. M., Khlevna, Iu. L. ～(2017) Knowledge structure in meta-methodology of project management Management of the development of complex systems. No. 29, pp. 78-85 [in Ukrainian].

8. Khlevna Iu. L., Teslya I. M. (2017) Creation and use of meta-methodology of project management in a crisis. XVI International Scientific and Practical Conference: Project Management of Society Development, KNUBA, pp. 199-200 [in Ukrainian].

9. Teslya I. M., Khlevna Iu. L.,. V. Oderembok (2016) Management of the development of a specified methodology of project management. Project Management, System Analysis and Logistics. Part 1: Series «Technical sciences», Vip. 18, K .: NTU, pp. 115-125 [in Ukrainian].

10.Teslya I. M., Khlevna Iu. L., Yehorchenkova N. I. (2017) Influences on the Formation of a Specified Project Management Methodology. Bulletin of the Cherkasy State Technological University. Series: Engineering, No. 2, pp. 45-54.

Iu. L. Khlevna, Ph.D., e-mail: yuliya.khlevna@gmail.com

Taras Shevchenko National University of Kyiv Volodymyrska str., 60, Kyiv, 01033

\section{METHOD OF EVALUATION AND MANAGEMENT OF EFFECTS ON FORMATION OF CUSTOMIZED PROJECT MANAGEMENT METHODOLOGY}

Project management meta-methodology (PMMM) is based on formalized tools of influence on different processes related to the implementation of project management methodology at a projectoriented enterprise. It is the main tool for influencing project-oriented enterprises in order to improve all management processes. The result of using PMMM is the creation of a concretized project man- 
agement methodology (CMMM) that integrates tools, processes, knowledge of existing project management methodologies with the knowledge, tools and processes of a particular enterprise. In essence, it allows to choose exactly those tools that most influence the efficiency of the project-oriented enterprise. At the same time, an important role in forming the CMMM tools is played by influences. Since PMMM is a system of influences, the formation of tools is also based on them, in other words, the influences of the PMMM form the tools of the CMMM.

The aim of the paper is to develop a method for selecting the impacts of PMMM on the forming of tools that will lead to the creation of a concretized methodology for project management that will improve the efficiency of enterprise project management.

Organizational, technical, financial and methodological classes of CMMM tools are defined in this paper. It is shown that the formation and functioning of the given classes of tools depends on the influence of the PMMM. The concept of the importance of the CMMM tool for project management is introduced. Coefficient of the importance will ensure the identification of those tools that are needed in the implementation of the PMMM. It is shown that each CMMM tool can be obtained with a certain probability, the value of which depends on the influence of PMMM. The objective function of estimating changes in probability of obtaining CMMM tools is proposed. The impact of the PMMM will lead to changes in the likelihood of forming CMMM tools. After these changes the target value of the objective function will or will not be achieved.

The method of selection of influences of PMMM on the formation of CMMM is developed, which is based on: determination of the coefficient of importance of CMMM tools; formation of a group of experts; formation of a plurality of controlled influences; expert method of forming CMMM tools with and without taking into account PMMM; calculation of the value of the target function of implementing CMMM tools. This will allow to define the positive impacts of the PMMM on the formation of CMMM and implement them when creating project management systems at project-oriented enterprises.

Keywords: project management meta-methodology, concretized project management methodology, impact, meta-methodology tools, projects, project management.

Стаття надійшла 01.06.2018.

Рецензенти: Ю. М. Тесля, д.т.н., професор,

Т. О. Прокопенко, д.т.н., доиент. 